\title{
EVALUASI KINERJA INSTALASI PENGOLAHAN AIR MINUM (IPAM) KARANGPILANG I PDAM SURYA SEMBADA KOTA SURABAYA SECARA KUANTITATIF
}

\author{
R. Gagak Eko Bhaskoro ${ }^{1, *}$, Tutut Ramadhan ${ }^{1}$ \\ 1) Prodi Teknik Lingkungan , Akademi Teknik Tirta Wiyata Magelang, Jl. Duku I No. 54, Perum \\ KORPRI-ABRI, Kota Magelang, 56115 \\ e-mail: gagak.water@akatirta.ac.id
}

\begin{abstract}
Abstrak
IPAM Karangpilang I merupakan salah satu instalasi pengolahan air yang di miliki PDAM Kota Surabaya yang melayani kebutuhan air bersih di Kota Surabaya dengan kapasitas $1.450 \mathrm{~L} / \mathrm{det}$. Supaya IPAM tetap dapat beroperasi secara optimal, maka diperlukan evaluasi terhadap IPAM ini. Penelitian bertujuan untuk : 1) Mengukur kinerja tiap-tiap unit Instalasi Pengolahan Air Minum (IPAM) Karangpilang I Kota Surabaya; 2) Membandingkan kualitas air produksi yang dihasilkan oleh IPAM Karangpilang I dengan standar PERMENKES No.492 2010; 3) Menganalisa hasil evaluasi IPAM Karangpilang I. Evaluasi IPAM dilakukan dengan observasi, wawancara, studi literatur, praktik lapangan. Hasil yang diperoleh dari penelitian ini adalah Kinerja setiap unit operasi belum berjalan secara optimal, yaitu pada unit Koagulasi, Sedimentasi, Filtrasi. Kualitas air produksi IPAM Karangpilang I sesuai dengan dengan Permenkes No 492 tahun 2010 tentang Kualitas Air. Berdasarkan hasil evaluasi secara keseluruhan instalasi IPAM Karangpilang I pada saat eksisting sudah dapat mengolah air dengan baik sehingga air yang diolah dapat memenuhi baku mutu air.
\end{abstract}

Kata Kunci : IPAM; Kualitas Air; Evaluasi

\begin{abstract}
IPAM Karangpilang I is one of the Water Treatment Plant (WTP) in PDAM Surabaya that serve the needs of clean water in the city of Surabaya with a capacity of 1,450 L. In order for IPAM to operate optimally, an evaluation of this WTP is required. The research aims to: 1) Measuring the performance of each unit of Drinking Water Treatment Plan (WTP) Karangpilang I Surabaya; 2) Comparing the quality of water produced by WTP Karangpilang I with PERMENKES standard No.492/2010; 3) Analyze the evaluation results of WTP Karangpilang I. The evaluation of WTP is done by observation, interview, literature study, field practice. The results obtained from this research is the performance of each unit of operation has not run optimally, namely on the unit Coagulation, Sedimentation, Filtration. The quality of water produced by WTP Karangpilang I in accordance with Permenkes No 492 of 2010 on Water Quality. Based on the results of the overall evaluation of the installation of WTP Karangpilang I at the existing time has been able to process water well so that treated water can meet the water quality standards.
\end{abstract}

Keywords: WTP; Water Quality; Evaluation

\section{Pendahuluan}

Pertumbuhan penduduk setiap tahunnya semakin meningkat. Seiring bertambahnya jumlah penduduk, akan menyebabkan peningkatan kebutuhan air untuk memenuhi kebutuhan masyarakat. Namun pertumbuhan penduduk ini juga menyebabkan penurunan kualitas air di sumber air baku karena aktivitas manusia dan penggunaan lahan di sekitar sumber. Air yang dapat dikonsumsi oleh penduduk di Indonesia harus memenuhi Peraturan Menteri Kesehatan Republik Indonesia No.492/MENKES/PER/IV/2010, yang meliputi syarat fisik, kimia dan biologi.

PDAM Surya Sembada Surabaya merupakan perusahaan jasa pemerintah penyedia layanan air bersih yang mempunyai sejumlah instalasi pengolahan 
air minum. Wilayah cakupan layanan PDAM Surya Sembada Kota Surabaya saat ini mencapai 536,983 ribu Sambungan Rumah (SR) dari jumlah penduduk 2.962.700 jiwa (Dinas Kependudukan dan Catatan Sipil Surabaya, 2016). Jumlah tersebut mencapai $92,5 \%$ daerah terlayani air bersih. PDAM Surya Sembada Kota Surabaya menargetkan peningkatan cakupan pelayanannya air bersih hingga mencapai 100\% pada tahun 2018 (Waluyo, 2016). Guna mendukung target ini harus diimbangi dengan kapasitas produksi yang ada. Instalasi Pengolahan Air Minum (IPAM) Karangpilang I merupakan salah satu instalasi pengolahan air yang di miliki PDAM Kota Surabaya, yang dibangun pada tahun 1990 dengan kapasitas 1.000 lt/dt. Pada tahun 2006 terjadi peningkatan kapasitas air produksi menjadi $1.450 \mathrm{lt} / \mathrm{dt}$ yang disebabkan bebagai faktor. Salah satu faktor peningkatan kapasitas produksi ialah bertambahnya pelanggan.

Penelitian ini bertujuan untuk (1) Mengukur kinerja tiap-tiap unit Instalasi Pengolahan Air Minum (IPAM) Karangpilang I Kota Surabaya; (2) Membandingkan kualitas air produksi yang dihasilkan oleh IPAM Karangpilang I dengan standar PERMENKES No.492/2010.

\section{Metodologi Penelitian}

\section{a. Persiapan}

Tahapan ini meliputi observasi persiapan administrasi, koordinasi tim serta perencanaan jadwal kegiatan.

\section{b. Pengumpullan Data}

Data yang dikumpulkan meliputi data primer dan data skunder:

1) Data primer yang dikumpulkan meliputi:

\begin{tabular}{ll}
\hline \multicolumn{1}{c}{ Jenis Data } & \multicolumn{1}{c}{ Uraian } \\
\hline Debit & Debit Pengolahan \\
Unit Koagulasi & Td, G, G.td, Headloss, \\
& Dimensi Unit, Tinggi \\
& Muka Air \\
Unit Flokulasi & Td, G, G.td, Kehilangan \\
& tekanan tiap bak (H), \\
& Dimensi unit, Tinggi \\
& Muka Air permukaan \\
Unit & Td, beban permut permukan \\
Sedimentasi & So, beban pon \\
& antara plat \\
& Kecepatan pengaliran \\
& Vo, Bilangan Reynold \\
& (Re) Bilangan Froude \\
& (Fr), Dimensi Unit \\
\hline
\end{tabular}

\begin{tabular}{cl}
\hline \multicolumn{1}{c}{ Jenis Data } & \multicolumn{1}{c}{ Uraian } \\
\hline Unit Filtrasi & Kecepatan Penyaringan \\
& $V_{F}$, Headloss, Kecepatan \\
& backwash maksimum \\
& $($ Vb), Porositas Pasir \\
& terekspansi (Pe), \\
& Maksimum pasir \\
& terekspansi $(f e)$, \\
& Ketinggian pasir \\
& terekspansi (Le), \\
& Dimensi Unit
\end{tabular}

2) Data Sekunder yang dikumpulkan adalah as built drawing IPA, laporan kualitas air, master plan IPA, kapasitas instalasi/produksi dan jumlah layanan.

\section{c. Metode Analisis}

1) Perhitungan dan Evaluasi Kondisi Eksisting Instalasi

Analisa sistem operasional unit bangunan instalasi dapat dilihat dari perbandingan antara hasil perhitungan menurut kondisi eksisting IPA mengenai parameter-parameter yang merupakan faktor penting dalam sistem operasional bangunan dengan kriteria desain perencanaan bangunan tersebut (Chamdan \& Purnomo, 2013)

\section{2) Analisis Sumber Air Produksi}

Analisa terhadap kualitas air produksi mengacu pada standar kualitas atau baku mutu air minum yang terdapat pada Keputusan Menteri Kesehatan No. 492 tahun 2010.

Analisa ini meliputi analisa kualitas air minum ditinjau dari parameter-parameter fisika dan kimia.

\section{Hasil dan Pembahasan}

\section{a. Deskripsi IPAM}

Karangpilang I merupakan IPAM dengan kapasitas 1.450 liter/detik yang dimiliki oleh PDAM Surya Sembada. Dibangun dengan kontruksi beton menggunakan unit pengolahan lengkap.

Sumber air baku yang diolah berasal dari Kali Surabaya dengan titik pengambilan air baku di pinggir kali sungai Surabaya yang berjarak \pm 800 meter dari IPAM Karangpilang I.

Area IPAM juga dilengkapi dengan beberapa bangunan pendukung antara lain Clean Water Storage, Backwash Water Storage, ruang pompa, gudang penyimpanan bahan kimia, bengkel, ruang genset, ruang staf dan operator, ruang panel, laboratorium dan mushola. 
Skema IPAM Karangpilang I dapat dilihat pada Gambar 1, sedangkan untuk diagram alur proses pengolahan air bersih dapat dilihat pada Gambar 2.

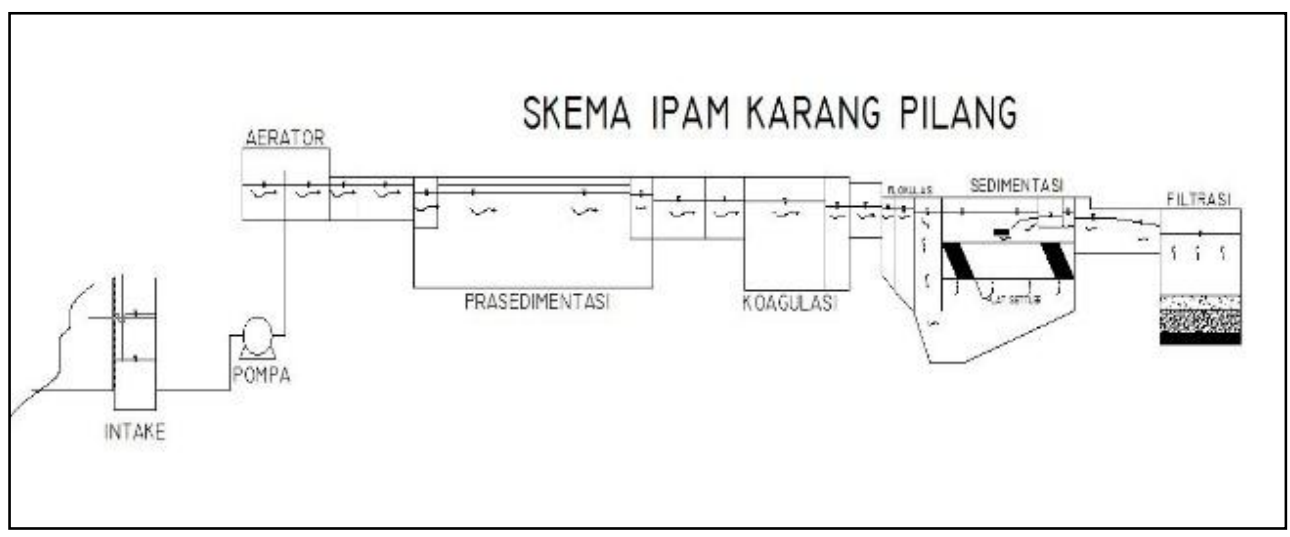

Gambar 1. Skema IPAM Karangpilang I

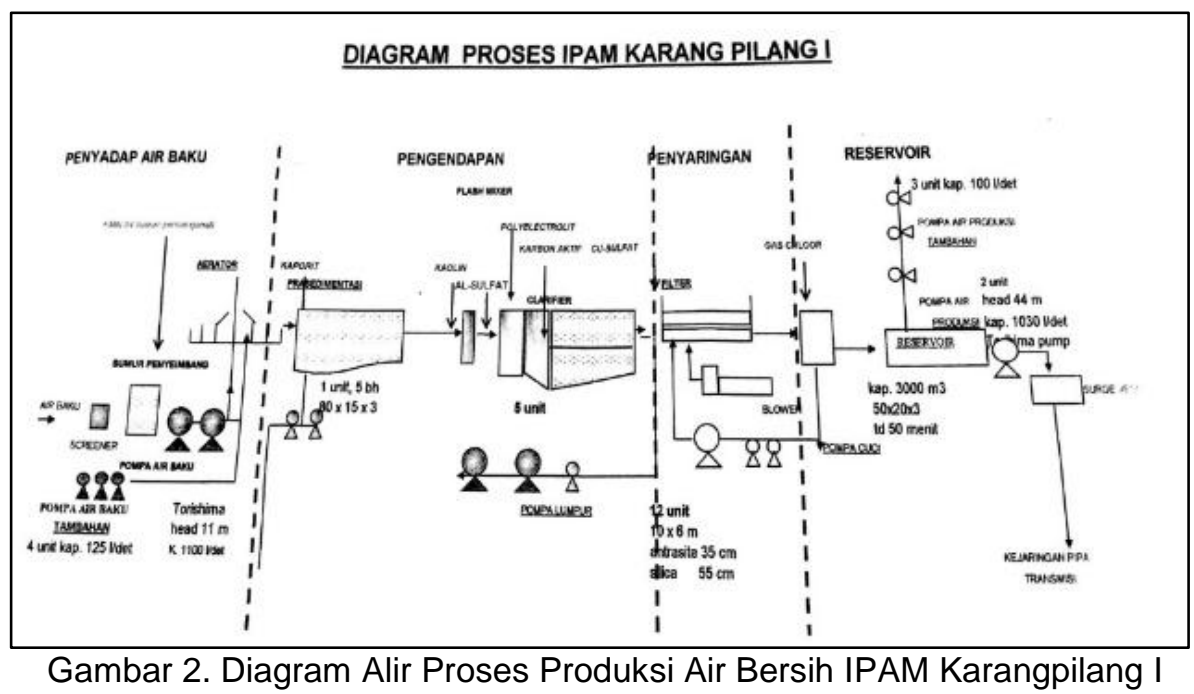

Intake

Intake atau bangunan penangkap air merupakan bangunan pengambilan untuk pengolahan air bersih. Intake merupakan bangunan untuk pengumpulan air baku yang akan dialirkan ke instalasi pengolahan air bersih.

Intake pada IPAM Karangpilang I menggunakan tipe River Intake yang terdiri atas sumur beton berdiameter $3-6 \mathrm{~m}$ yang dilengkapi 2 atau lebih pipa besar yang disebut penstock. Pipa-pipa tersebut dilengkapi dengan katup sehingga memungkinkan air memasuki intake secara berkala. Air yang terkumpul dalam sumur kemudian dipompa dan dikirim kedalam instalasi pengolahan. River Intake terletak pada bagian hulu kota untuk menghindari pencemaran oleh air buangan. Air baku pada intake dipompa dan disalurkan melalui pipa transmisi air baku menuju IPAM Karangpilang I.
Aerator

Bangunan aerator berfungsi untuk meningkatkan kontak antara udara dengan air. Proses aerasi bertujuan untuk meningkatkan konsentrasi oksigen di dalam air. Peningkatan konsentrasi oksigen di dalam air ini akan memberikan berbagai manfaat dalam pengolahan air.

\section{Prasedimentasi}

Bangunan Prasedimentasi digunakan untuk dapat mengendapkan partikel kasar (discrite particle) sebelum proses koagulasi. Bangunan prasedimentasi terdiri atas empat persegi panjang yang dibagi dalam 5 (Lima) kompartemen, untuk memudahkan dalam pemeliharaan (pengurasan). Bangunan ini memiliki panjang 80 meter, lebar 15 meter, dan tinggi 3 meter perkompartemen. 


\section{Unit Koagulasi}

Unit Koagulasi pada IPAM Karangpilang I menggunakan tipe pengadukan hidrolis, dimana pengadukan cepat dilakukan dengan memanfaatkan pintu air di dalam bak (pengadukan dengan sistem umbulan). Proses koagulasi dilakukan dengan cara menyemprotkan (spray) cairan koagulan (Alumcsulfat).

\section{Unit Flokulasi}

Bangunan Bak Flokulasi di IPAM Karangpilang I berjumlah 5 buah. Bak flokulasi berfungsi untuk proses pengadukan lambat agar membentuk flok yang lebih besar dari flok awal. Tiap bak flokulasi terdiri dari 3 kompartemen dengan ukuran yang berbeda-beda.

\section{Unit Sedimentasi}

Setelah air melalui Unit Flokulasi, selanjutnya air menuju Zona Sedimentasi yang arah alirannya ke atas.

Unit Sedimentasi pada IPAM Karangpilang I berjumlah 5 bak. Pada Unit Sedimentasi terdapat plat settler yang tampak di permukaan dilengkapi dengan Gutter dan V- Notch. Plat settler berfungsi sebagai tempat menempelnya flok-flok pada proses sedimentasi.

\section{Unit Filtrasi}

Setelah dilakukan proses pengendapan di sedimentasi kemudian air menuju Unit Filtrasi. Media filter yang digunakan pasir silica. Unit filtrasi pada IPAM Karangpilang I menggunakan media pasir kuarsa. Unit ini berfungsi untuk menyaring kotoran dan partikel-partikel yang sangat halus, serta flok-flok dari partikel tersuspensi, selain itu juga untuk mengurangi kadar Fe dan Mn.
Kadar Fe yang rendah akan mengurangi kemungkinan timbulnya karat pada perlengkapan perpipaan dan lain-lain. Dengan sand filter ini kandungan $\mathrm{Fe}$ setelah aerasi dapat menurun hingga $86,81 \%$ (Hardyanti, Nurandani, \& Fitri, 2006).

Proses filtrasi dimaksudkan untuk menyisihkan partikel koloid yang tidak dapat disisihkan pada proses sebelumnya dan juga untuk mengurangi jumlah bakteri organisme lain (Gaib, Tanudjaja, \& Hendratta, 2016).

Setelah melalui proses penyaringan pada Unit Filtrasi kemudian air dialirkan dalam pipa di injeksikan gas klor sebelum masuk reservoir dan air siap di distribusikan.

\section{b. Kinerja IPAM Karangpilang I}

\section{Debit Pengolahan}

Pengukuran debit pengolahan dilakukan dengan menggunakan Ultrasonic Flow Meter (UFM). Setelah dilakukan pengukuran, diperoleh debit pengolahan rata-rata di IPAM Karangpilang I adalah $1,368\left(\mathrm{~m}^{3} / \mathrm{s}\right)$.

\section{Unit Koagulasi}

Koagulasi pada IPAM Karangpilang
menggunakan sistem Umbulan.
Keuntungan pengadukan cepat dengan
umbulan ini sangat menghemat energi,
karena hanya memanfaatkan perbedaan
tinggi tanpa menggunakan energi listrik.

Setelah dlakukan pengukuran dimensi dan pengolahan data, diperoleh hasil yang dapat dilihat pada Tabel 1.

Tabel 1. Hasil Pengolahan Data Unit Koagulasi dan Perbandingan dengan Standar AWWA

\begin{tabular}{|c|c|c|c|c|c|}
\hline No & Uraian & Satuan & Nilai & $\begin{array}{l}\text { Standard } \\
\text { AWWA }\end{array}$ & Ket. \\
\hline 1 & Waktu Kontak (td) & Detik & 57,26 & $30-120$ & Sesuai \\
\hline 2 & $\begin{array}{l}\text { Gradien } \\
\text { Kecepatan (G) }\end{array}$ & $\operatorname{detik}^{-1}$ & 458,21 & $500-1000$ & $\begin{array}{l}\text { Kurang } \\
\text { Sesuai }\end{array}$ \\
\hline 3 & G.td & - & 26236,57 & $>2 \times 10^{4}$ & Sesuai \\
\hline
\end{tabular}

(Sumber : Perhitungan Eksisting Unit Koagulasi dan Standard AWWA)

Nilai Gradien Kecepatan (G) pada unit flokulasi kurang sesuai, dikarenakan head 
loss yang terlalu kecil. Akibatnya, bahan koagulan (alumsulfat) tidak tercampur secara merata.

Ketidakkonstanan nilai G menyebabkan flok akan hancur kembali. Nilai gradien kecepatan dipengaruhi oleh ketinggian air. Untuk menghindari naik turunnya nilai $G$, maka besarnya gradien kecepatan perlu diturunkan tiap tahapannya dengan mengatur katup aliran tiap kompartemen agar tinggi air dapat turun secara konstan (Arifiani \& Hadiwidodo, 2007).

Kecilnya nilai $\mathrm{G}$ disebabkan oleh bukan pintu di bak 1 menuju ke bak 2 terlalu besar mengakibatkan headloss terlalu kecil sehingga gradien kecepatan (G) tidak terpenuhi.

Salah satu cata mengatasi hal ini yaitu dengan pemasangan alat ukur berupa duga air pada bukaan pintu. Alat ini dipasang untuk mengetahui bukaan pintu yang sesuai dan mengatur tinggi bukaan pintu tersebut agar nilai gradien kecepatan (G) dan nilai G.td sesuai. Nilai G dan Gtd masih dibawah nilai kriteria desain dapat mengakibatkan pencampuran koagulan tidak homogen.

(Hermanto, Yusuf, \& Jati, 2014)

\section{Unit Flokulasi}

Unit Flokulasi pada IPAM Karangpilang I berjumlah 5 unit. Unit Flokulasi dilengkapi dengan bak flokulasi berbentuk persegi panjang dengan alas prisma yang berjumlah 3 kompartemen dan dilengkapi dengan pintu air yang berbentuk persegi panjang dan lingkaran. Proses yang terjadi pada unit flokulasi adalah pengadukan lambat dengan melalui beton berlubang.

Setelah dilakukan pengukuran dimensi dan pengolahan data di Unit Flokulasi, diperoleh hasil bahwa Unit Flokulasi telah sesuai Kriteria AWWA.

Flokulasi berfungsi untuk memperbesar inti flok yang telah terbentuk ada unit koagulasi. Flokulasi dengan sistem hidrolik memanfaatkan beda ketinggian air. tidak memerlukan energi tambahan (mekanik) sehingga dapat menghemat energi (Priambodo \& Indaryanto, 2017)

\section{Unit Sedimentasi}

Bangunan sedimentasi berbentuk persegi panjang. Bak sedimentasi juga dilengkapi dengan gutter yang berfungsi sebagai saluran pelimpah dan saluran menuju bak filter. Untuk memperkecil beban permukaan bak sedimentasi dilengkapi dengan pipe settler.

Setelah dlakukan pengukuran dimensi dan pengolahan data, diperoleh hasil yang dapat dilihat pada Tabel 2.

Tabel 2. Rekapitulasi hasil perhitungan Unit Sedimentasi dan Perbandingan dengan Standar AWWA

\begin{tabular}{|c|c|c|c|c|c|}
\hline NO & URAIAN & SATUAN & NILAI & $\begin{array}{c}\text { STANDAR } \\
\text { AWWA } \\
\end{array}$ & KET \\
\hline 1 & Debit (Q) & $\mathrm{m}^{3} / \mathrm{det}$ & 0,2736 & - & - \\
\hline 2 & Waktu Kontak (td) & Jam & 0,69 & $0,5-1$ & Sesuai \\
\hline 3 & $\begin{array}{l}\text { Beban Permukaan } \\
\text { Eksternal (So) }\end{array}$ & $\mathrm{m}^{3} / \mathrm{m}^{2} / \mathrm{jam}$ & 7,45 & $7-10$ & Sesuai \\
\hline 4 & $\begin{array}{c}\text { Beban Permukaan Internal } \\
\text { (So') }\end{array}$ & $\mathrm{m}^{3} / \mathrm{m}^{2} / \mathrm{jam}$ & 0,46 & $0,5-0,8$ & $\begin{array}{l}\text { Kurang } \\
\text { Sesuai }\end{array}$ \\
\hline $\begin{array}{l}5 \\
6 \\
7\end{array}$ & $\begin{array}{l}\text { Kemiringan Pipa Settler } \theta \\
\text { Diameter Pipa Settler } \\
\text { Ketebalan Pipa Settler }\end{array}$ & $\begin{array}{l}\circ \\
M \\
M\end{array}$ & $\begin{array}{c}54 \\
0,06 \\
0.01\end{array}$ & $\begin{array}{c}30-60 \\
0,05-0,1 \\
0,002-0,005\end{array}$ & $\begin{array}{l}\text { Sesuai } \\
\text { Sesuai } \\
\text { Sesuai }\end{array}$ \\
\hline 8 & Tinggi Vertikal Pipa Settler & M & 1,3 & $1-1,2$ & $\begin{array}{l}\text { Kurang } \\
\text { Sesuai }\end{array}$ \\
\hline $\begin{array}{c}9 \\
10 \\
11 \\
12 \\
13\end{array}$ & $\begin{array}{c}\text { Bilangan Froude } \\
\text { Bilangan Reynold } \\
\text { Jumlah Pipa Settler } \\
\text { Kecepatan Pengaliran (Vo) } \\
\text { Kecepatan di inlet }\end{array}$ & $\begin{array}{c}- \\
- \\
\text { Buah } \\
\text { m/det } \\
\text { m/det }\end{array}$ & $\begin{array}{c}5,29 \times 10^{-5} \\
39,, 52 \\
44160 \\
0,002549 \\
0,03\end{array}$ & $\begin{array}{c}>1 \times 10^{-5} \\
<500 \\
- \\
- \\
-\end{array}$ & $\begin{array}{l}\text { Sesuai } \\
\text { Sesuai } \\
- \\
- \\
-\end{array}$ \\
\hline 14 & $\begin{array}{l}\text { Kecepatan di Outlet } \\
\text { (Gutter) }\end{array}$ & $\mathrm{m} / \mathrm{det}$ & 0,019 & - & - \\
\hline
\end{tabular}

(Sumber : Perhitungan Eksisting Unit Sedimentasi dan Standard AWWA) 
Pada unit Sedimentasi terdapat beberapa parameter yang belum masuk kedalam kriteria AWWA. Beban permukaan dan tinggi plat settler yang tidak sesuai kriteria akan menyebabkan aliran air menjadi tidak laminer. Namun untuk nilai $\mathrm{N}_{\mathrm{Re}}$ dan $\mathrm{N}_{\mathrm{fr}}$ dari hasil perhitungan diketahui aliran sudah laminer $\left(\mathrm{N}_{\mathrm{Re}}<500\right)$ dan untuk keseragaman aliran air dapat dilihat $\left(\mathrm{N}_{\mathrm{fr}}>10^{-5}\right)$ sehingga keseragaman aliran sudah terjadi (Montgomery, 1985). Agar beban permukan internal so' dan tinggi plat settler memenuhi kriteria, dapat dilakukan perubahan ukuran diameter pipa settler dari $6 \mathrm{~cm}$ menjadi $7 \mathrm{~cm}$ atau $0,07 \mathrm{~m}$ dan tinggi plat settler menjadi 1,2 m.

\section{Unit Filtrasi}

Proses penyaringan air untuk memisahkan flok-flok yang masih terbawa dari Unit Sedimentasi dilakukan di Unit Filtrasi. Pada IPAM Karangpilang I terdapat 12 Unit Filtrasi yang hanya berkerja 9 unit. Unit Filtrasi ini persegi panjang dengan tipe saringan menggunakan Saringan Pasir Cepat (Rapid Sand Filter).

Parameter operasi utama yang diukur dalam unit filtrasi adalah kecepatan filtrasi dan kecepatan backwash disamping ada parameter ukur lain untuk desain yakni headloss saat filtrasi dan headloss saat backwash yang dipengaruhi oleh bentuk, jenis dan ukuran media (Utami, Oktiawan, \& Wardana, 2016).

Pada unit Filtrasi terdapat satu parameter yang belum sesuai dengan kriteria AWWA yaitu tebal media pasir sebesar $50 \mathrm{~cm}$, dimana seharusnya tebal media pasir berada pada range $60-90 \mathrm{~cm}$.

Akibatnya, intensitas waktu untuk backwash menjadi lebih sering sehingga kehilangan air saat backwash menjadi lebih tinggi. Media pasir yang kurang akan menyebabkan penyaringan partikel menjadi berkurang. Selain itu kendala IPAM Karangpilang I adalah nozzle yang sering mengalami penyumbatan oleh media pasir. Hal ini dapat menyebabkan pasir masuk ke dalam reservoir. Unit filtrasi harus segera diperbaiki apabila tidak akan membebani kinerja bak filter yang lain.

\section{Kualitas air Produksi IPAM Karangpilang I}

Analisis kualitas air melalui uji laboratorium sangat menentukan, karena hasil dari analisis dapat bermanfaat untuk mengetahui boleh tidaknya air tersebut digunakan oleh penduduk untuk keperluan sehari - hari, kendala yang dihadapi dalam hal kualitas air, dan solusinya bagi penduduk (Burhan, Nagu, \& Anwar, 2017).

Analisa kualitas air Produksi IPAM Karangpilang I dilakukan oleh Lab. PDAM Surya Sembada pada bulan Maret-Mei 2016. Parameter yang dianalisa adalah suhu, kekeruhan, pH, Zat Organik, Sulfida, Klorin Bebas, Detergen, Fecal Coli dan Total Coli. Setelah dibandingkan dengan Permenkes No. 492 Tahun 2010, kualitas air produksi IPAM Karangpilang I telah sesuai dengan baku mutu.

Berdasarkan hasil evaluasi secara keseluruhan instalasi IPAM Karangpilang I, terdapat beberapa nilai yang tidak sesuai dengan kriteria desain AWWA. Namun, IPAM ini sudah dapat mengolah air dengan baik sehingga air yang diolah dapat memenuhi baku mutu.

\section{Kesimpulan}

Dari hasil penelitian, dapat disimpulkan bahwa:

1. Terdapat beberapa parameter yang tidak sesuai dengan kriteria desain menurut AWWA. Meski begitu hasil dari pengolahan masih cukup bagus. Parameter yang tidak sesuai kriteria yaitu:

a. Koagulasi : Gradien kecepatan (G) pada unit koagulasi sebesar 458,21 detik $^{-1}$ kurang sesuai range 500-1000 detik ${ }^{-1}$.

b. Sedimentasi : Beban Permukaan Internal dan Tinggi vertikal pipe settler. Beban permukaan internal So' sebesar 0,46 $\mathrm{m}^{3} / \mathrm{m}^{2} /$ jam kurang sesuai kriteria dengan kriteria $0,5-0,8 \mathrm{~m}^{3} / \mathrm{m}^{2} / \mathrm{jam}$, dan tinggi plat settler kurang sesuai kriteria yaitu sebesar 1,3 m kriteria yang diijinkan sebesar $(1-1,2)$. c. Filtrasi : tebal media pasir sebesar 50 $\mathrm{cm}$ range $(60-90 \mathrm{~cm})$.

2. Kualitas air produksi IPAM Karangpilang I sudah sesuai dengan dengan Permenkes No 492 tahun 2010 tentang Kualitas air.

Ucapan Terimakasih: Ucapan terimakasih kami sampaikan kepada pihak PDAM Surya Sembada Kota Surabaya dan pihak lain yang tidak dapat kami sebutkan satu persatu yang telah membantu selesainya penelitian ini. 


\section{Daftar Pustaka}

Arifiani, N. F., \& Hadiwidodo, M. (2007). Evaluasi Desain Instalasi Pengolahan Air PDAM Ibu Kota Kecamatan Prambanan Kabupaten Klaten. Jurnal Presipitasi, 3(2), 7885.

AWWA, ASCE. (2012). Water Treatment Plan Design. Fifth Edition. Newyork: The McGraw-Hill Companies Inc.

Burhan, N., Nagu, N., \& Anwar, C. (2017). Tinjauan Instalasi Pengolahan Air Bersih PDAM . Jurnal Sipil Sains, 07(14), 13-22.

Chamdan, A., \& Purnomo, A. (2013). Kajian Kinerja Teknis Proses dan Operasi Unit Koagulasi-FlokulasiSedimentasi pada Instalasi Pengolahan Air (IPA) Kedungguling PDAM Sidoarjo. Jurnal Teknik POMITS , 2(2), 118-123.

Gaib, D. T., Tanudjaja, L., \& Hendratta, L. A. (2016). Perencanaan Peningkatan Kapasitas Produksi Air Bersih Ibukota Kecamatan Nuangan. Jurnal Sipil Statik, 4(8), 481-490.

Hardyanti, Nurandani, \& Fitri, N. D. (2006). Studi Evaluasi Instalasi Pengolahan Air Bersih untuk Kebutuhan Domestik dan Non Domestik (Studi Kasus Perusahaan
Tekstil Bawen Kab. Semarang). Jurnal Presipitasi , 1(1), 37-42.

Hermanto, J., Yusuf, W., \& Jati, D. R. (2014). Evaluasi dan Optimalisasi Instalasi Pengolahan Air Minum (IPA I) Sungai Sengkuang PDAM Tirta Pancur Aji Kota Sanggau. Jurnal Mahasiswa Teknik Lingkungan Untan Vol 1, No. 1.

Montgomery, J. M. (1985). Water Treatment Principle and Design. Canada: John Wiley and Sons Inc.

Priambodo, E. A., \& Indaryanto, H. (2017). Perancangan Unit Instalasi Pengolahan Alr Minum Kampus Institut Teknologi Sepuluh Nopember. Jurnal Teknik ITS Vol 6, No. 1, ISSN 2337-3539 (2301-9271 Print).

Utami, D. S., Oktiawan, W., \& Wardana, I. W. (2016). Design Pengolahan Air Minum untuk Optimalisasi Pelayanan Air Bersih Wilayah Pelayanan Luar Kota Kecamatan Sukaharjo Kabupaten Sukoharjo . Jurnal Teknik Lingkungan Vol. 5 No. 1, Universitas Diponegoro Semarang.

Waluyo, Y. (2016, April 12). Tahun Ini, PDAM Surabaya Targetkan Pendapatan Rp 650 Miliar. Retrieved from Bisnis.com: http://industri.bisnis.com/read/2016 0412/45/537301/tahun-ini-pdamsurabaya-targetkan-pendapatanrp650-miliar 